\title{
Dietary intakes of citrus fruit and risk of gastric cancer incidence: an adaptive meta-analysis of cohort studies
}

\author{
Jong-Myon Bae, Eun Hee Kim \\ Department of Preventive Medicine, Jeju National University School of Medicine, Jeju, Korea
}

\begin{abstract}
OBJECTIVES: In the context of supplementary antioxidants having no anticancer effect, it is important to update the meta-analysis to evaluate whether there is an association between intake of citrus fruit and gastric cancer risk.

METHODS: The list of articles to be searched was established using citation discovery tools provided by PubMed and Scopus. The effect size of each article to be used in meta-analysis was calculated using the interval-collapse method. Summary effect size (sES) and $95 \%$ confidence intervals (CI) were obtained by conducting this metaanalysis. Random effect dose-response meta-regression (DRMR) was performed to investigate the dose-response relationship.

RESULTS: A total of five cohort studies were selected. The result was $13 \%$ reduction of gastric cancer according to the intake of citrus fruit (sES, $0.87 ; 95 \% \mathrm{CI}, 0.76$ to 0.99 ; I-squared $=69.6 \%$ ). In subgroup analysis, it was found that the intake of citrus fruit inhibited cardia gastric cancer (CGC) (sES, $0.67 ; 95 \%$ CI, 0.55 to 0.81 ; I-squared $=46.1 \%$ ) and as a result of DRMR, $100 \mathrm{~g}$ of citrus fruit intake per day inhibits CGC by $40 \%$ (relative risk, $0.60 ; 95 \% \mathrm{CI}, 0.44$ to 0.83 ).
\end{abstract}

CONCLUSIONS: It is suggested that the intake of citrus fruit inhibits the development of CGC. This conclusion can be used as a primary prevention measure in the future when the incidence of CGC may be on the rise.

KEY WORDS: Gastric neoplasms, Risk factors, Citrus fruit, Meta-analysis

\section{INTRODUCTION}

As one of the main types of primary cancers, gastric cancer is the fourth and fifth most common cancer worldwide in men and women, respectively, and has the highest incidence rate in Far East Asia, which includes Korea [1].The observance of such geographical characteristics has been attributed to chronic Helicobacter pylori (Hp) infection [2-4]. However, the fact that less than $0.5 \%$ of patients with $\mathrm{Hp}$ infection acquire stomach can-

Correspondence: Jong-Myon Bae

Department of Preventive Medicine, Jeju National University School of Medicine, 102 Jejudaehak-ro, Jeju 63243, Korea

Tel: +82-64-755-5567, Fax: +82-64-725-2593, E-mail: jmbae@jejunu.ac.kr

Received: Jun 27, 2016, Accepted: Jul 25, 2016, Published: Jul 25, 2016

This article is available from: http://e-epih.org/

(C) 2016, Korean Society of Epidemiology

(C) This is an open-access article distributed under the terms of the Creative Commons Attribution License (http://creativecommons.org/licenses/by/4.0/), which permits unrestricted use, distribution, and reproduction in any medium, provided the original work is properly cited. cer suggests that other risks or protective factors may be involved in contributing to this profile of geographical characteristics [5-7].

In 2008, Bae et al. [8] published a systematic review (SR) of epidemiologic studies that had been published until April 2007; the SR investigated the relationship between citrus fruit intake and gastric cancer risk. This meta-analysis, which reviewed a total of 14 analytical epidemiological studies, showed that dietary intake of citrus fruit reduced gastric cancer risk by $28 \%$ (summary effect size [sES], 0.72; 95\% confidence intervals [CI], 0.64 to 0.81 ). However, results of two cohort studies included in the meta-analysis lacked statistical significance (sES, 0.87; $95 \mathrm{CI}$, 0.67 to 1.13). It was concluded that since only a small number of papers were published on this topic, and case-control studies tend to contain more epidemiological errors than cohort studies, additional studies would be needed in the future $[9,10]$.

On the one hand, Fang et al. [11] published SR results in 2015 on cohort studies that had been published until June 2015 that identified dietary factors associated with gastric cancer risk. The 
meta-analysis results on eight cohort studies [12-19] with regard to citrus fruit intake were marginally significant with sES 0.90 (95\% CI, 0.82 to 1.00). However, among these eight selected cohorts, Botterweck et al. [12] and Steevens et al. [17] investigated the same cohort called as the Netherlands Cohort Study, and likewise, González et al. [13] and Gonzalez et al. [16] investigated the same cohort named as the European Prospective Investigation into Cancer and Nutrition Study. That is to say, Fang et al. [11] conducted a meta-analysis without taking into account the redundancy of cohort sources. In order to obtain valid results, cohort studies with short follow-up periods among cohort studies with the same participants $[12,13]$ should be excluded from the analysis. Moreover, analyzing cohort studies that look at cancer mortality alongside those that look at cancer incidence, as in the case of McCullough et al. [14] and Jansen et al. [15], poses a problem to epidemiological inference [20]. For these reasons, Fang et al. [11] needs to re-evaluate and re-meta-analyze the cohort studies selected for the metaanalysis. Namely, there is a need to perform an adaptive metaanalysis.

Therefore, this study aims to perform an adaptive meta-analysis on cohort studies published until December 2015 in order to overcome the shortcomings of the two previous SRs $[8,11]$ and improve validity.

\section{MATERIALS AND METHODS}

\section{Related article search and selection}

Cohort studies that investigated the relationship between dietary intake of citrus fruit and gastric cancer risk were selected for this study. Related articles were selected through a threestep process involving searching in databases, examining titles and abstracts, and reviewing literature content, as suggested by preferred reporting items for SRs and meta-analyses [21].

The data searching was done manually rather than electronically. This is because two SRs $[8,11]$ had been previously published, and accordingly, it would be more efficient to do an adaptive meta-analysis that updates the past literature [22-25]. In Bae et al. [8] and Fang et al. [11], for eight articles selected for meta-analysis, lists of articles to be searched were created by using the citation discovery tools (CDT) that served 'Cited' 'Similar' and 'Related' options, provided by PubMed (http:// www.ncbi.nlm.nih.gov/pubmed) and Scopus (www.scopus. com). The final publication date was set to December 31, 2015. In addition, manual searching was done to check if a SR had already been published on the hypothesis in question, and more lists were created. Lists made manually and through the CDT were combined, and duplicated lists were eliminated.

For the screening stage, studies were excluded if they fell into the following criteria based on their titles and abstracts: (1) laboratory experiments, (2) expert/SRs, and (3) descriptive studies. Studies that passed the screening process then moved on to the third stage for eligibility assessment. Copies of each study were collected and evaluated, and cohort studies that met the following criteria were sequentially excluded: (4) analytical studies that did not provide information necessary for the meta-analysis, (5) case-control studies, (6) gastric cancer mortality-based cohort studies, and (7) cohort studies that were duplicated as a result of extending a follow-up period. The remaining studies after applying the seven exclusion criteria were selected as the final articles to be used in the meta-analysis.

\section{Statistical analysis}

For each study, we looked at the cohort data source, the average length of follow-up period, the number of participants in the cohort as well as the number of cases who developed cancer, the method of investigating the quantity and unit of dietary citrus fruit intake, the adjusted relative risk (aRR) obtained after adjusting for confounders for each distribution of dietary intake and the corresponding 95\% CIs, and whether any of the adjusted confounding factors controlled the total energy intake and history of Hp infection. In the cases where an aRR was reported separately based on sex (male, female) and anatomical region (cardia, non-cardia), we considered the aRRs as separate datasets instead of combining them into one.

For aRR of each dataset to be used in the meta-analysis, the 'interval collapsing' method (ICM) was used instead of the 'high-

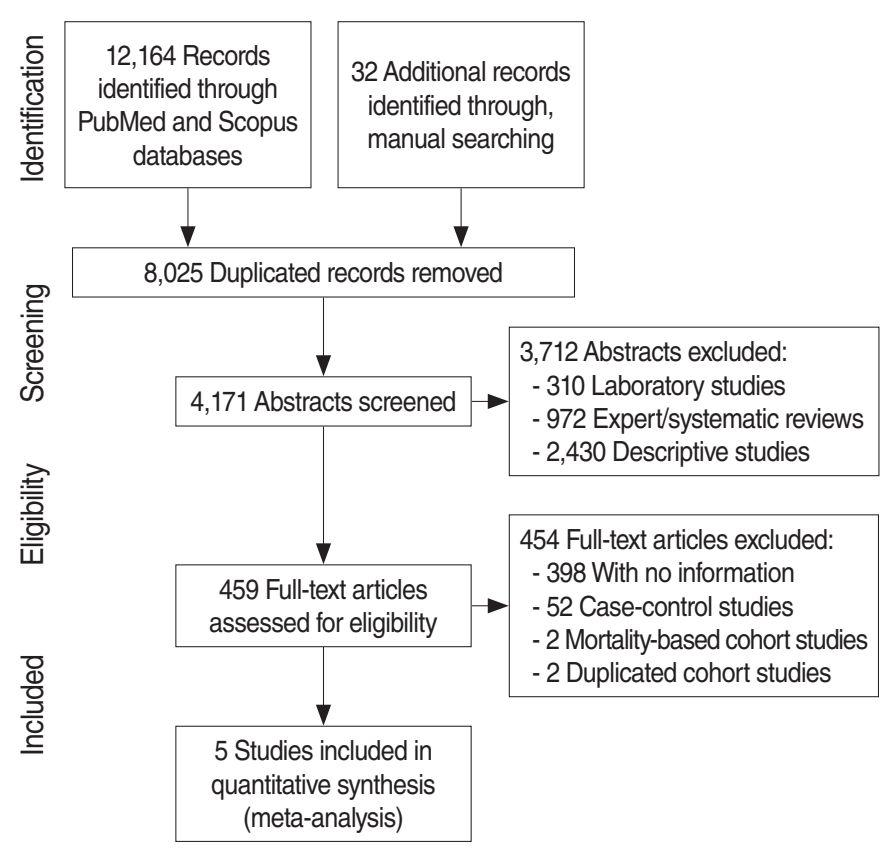

Figure 1. Flow chart of article selection. 
est vs. lowest intake' method (HLM). This is because ICM utilizes a greater amount of information than HLM and therefore improves statistical accuracy [26]. In an ICM, effect sizes are suggested for each level of intake of citrus fruits within a dataset of a study, and an effect size obtained from a meta-analysis of a random effect model (REM) and the corresponding 95\% CI are set as the effect size of the study. A REM meta-analysis was performed again on the effect size of each study to calculate an sES and the corresponding 95\% CI. The meta-analysis was con- sidered to contain heterogeneity if I-squared value (\%) was greater than or equal to $50 \%$. To detect any publication bias, a funnel plot and Egger's test for small-study effects were performed $[27,28]$. Additionally, a subgroup analysis was performed for each sex and stomach region.

In addition, in order to study the dose-response relationship for different quantities of citrus fruit intake, random effects doseresponse meta-regression (RE-DRMR) was performed [29]. For dose determination, a median value within each interval was

Table 1. The selected cohort studies for gastric cancer incidence

\begin{tabular}{|c|c|c|c|c|c|c|c|c|c|c|}
\hline $\begin{array}{l}\text { First author } \\
\text { (year of publi- } \\
\text { cation) [refer- } \\
\text { ence number] }\end{array}$ & $\begin{array}{c}\text { Cohort } \\
\text { population }\end{array}$ & $\begin{array}{l}\text { Size of cohort } \\
\& \text { Incident } \\
\text { cases (year } \\
\text { of follow-up) }\end{array}$ & $\begin{array}{l}\text { Measure } \\
\text { of intake } \\
\text { (units) }\end{array}$ & Citrus fruits & $\begin{array}{l}\text { Quantity of } \\
\text { intake }\end{array}$ & $\begin{array}{c}\text { Adjusted } \\
\text { RR }\end{array}$ & $95 \% \mathrm{Cl}$ & $\begin{array}{l}\mathrm{p} \text { for } \\
\text { trend }\end{array}$ & $\begin{array}{c}\text { Adjusted } \\
\text { for total } \\
\text { energy } \\
\text { intake }\end{array}$ & $\begin{array}{c}\text { Adjusted for } \\
\text { Helicobacter } \\
\text { pylori } \\
\text { infection }\end{array}$ \\
\hline $\begin{array}{l}\text { Freedman } \\
\text { (2008) [19] }\end{array}$ & $\begin{array}{l}\text { NIH-AAPR Diet } \\
\text { and Health } \\
\text { Study }\end{array}$ & $\begin{array}{c}490,802 \& 394 \\
(4.5)\end{array}$ & $\begin{array}{l}\text { FFQ (daily } \\
\text { serving } \\
/ 1,000 \mathrm{~K} \\
\text { calories) }\end{array}$ & $\begin{array}{l}\text { Oranges, } \\
\text { tangerines, } \\
\text { tangelos, } \\
\text { grapefruits }\end{array}$ & $\begin{array}{l}0.08 \\
0.46 \\
1.12 \\
0.08 \\
0.46 \\
1.12\end{array}$ & $\begin{array}{l}1.00 \\
0.73 \\
0.88 \\
1.00 \\
1.15 \\
1.36\end{array}$ & $\begin{array}{c}\text { Cardia } \\
0.52,1.03 \\
0.62,1.23 \\
\text { Non-cardia } \\
0.80,1.67 \\
0.96,1.94\end{array}$ & - & Yes & No \\
\hline Li (2010) [32] & $\begin{array}{l}\text { Ohsaki Cohort } \\
\text { Study }\end{array}$ & $\begin{array}{c}42,470 \& 313 \\
\text { (9) }\end{array}$ & FFQ (times) & Citrus & $\begin{array}{c}\leq 2 \\
3-4 \\
\text { Daily }\end{array}$ & $\begin{array}{l}1.00 \\
0.95 \\
0.94\end{array}$ & $\begin{array}{c}- \\
0.76,1.18 \\
0.74,1.20\end{array}$ & 0.63 & Yes & No \\
\hline $\begin{array}{l}\text { Epplein (2010) } \\
\text { [18] }\end{array}$ & $\begin{array}{l}\text { Shanghai } \\
\text { Women's and } \\
\text { Men's Health } \\
\text { Studies }\end{array}$ & $\begin{array}{c}132,311 \& 338 \\
(13)\end{array}$ & FFQ (g/d) & $\begin{array}{l}\text { Tangerines, } \\
\text { organs, } \\
\text { grapefruit }\end{array}$ & $\begin{array}{c}\leq 6.1 \\
>6.1-17.7 \\
>17.7-31.9 \\
>31.9 \\
\leq 1.6 \\
>1.6-\leq 6.3 \\
>6.3-\leq 18.0 \\
\leq 18.0\end{array}$ & $\begin{array}{l}1.00 \\
1.00 \\
1.05 \\
0.94 \\
1.00 \\
0.84 \\
1.02 \\
0.70\end{array}$ & $\begin{array}{c}\text { Women } \\
0.68,1.46 \\
0.71,1.53 \\
0.62,1.42 \\
\text { Men } \\
0.52,1.36 \\
0.65,1.62 \\
0.41,1.18\end{array}$ & 0.86 & Yes & No \\
\hline $\begin{array}{l}\text { Steevens } \\
\text { (2011) [17] }\end{array}$ & $\begin{array}{l}\text { The Nether- } \\
\text { lands Cohort } \\
\text { Study on diet } \\
\text { and cancer }\end{array}$ & $\begin{array}{c}4,035 \& 616 \\
(16.3)\end{array}$ & $\mathrm{FFQ}(\mathrm{g} / \mathrm{d})$ & $\begin{array}{l}\text { Lemon (juice), } \\
\text { grapefruit } \\
\text { (juice), } \\
\text { mandarins, } \\
\text { orange } \\
\text { (juice) }\end{array}$ & $\begin{array}{r}0 \\
8 \\
33 \\
77 \\
156 \\
0 \\
8 \\
33 \\
77 \\
156\end{array}$ & $\begin{array}{l}1.00 \\
0.76 \\
0.54 \\
0.55 \\
0.38 \\
1.00 \\
0.86 \\
0.89 \\
0.99 \\
0.80\end{array}$ & $\begin{array}{c}\text { Cardia } \\
0.47,1.22 \\
0.32,0.92 \\
0.32,0.94 \\
0.21,0.69 \\
\text { Non-cardia } \\
0.61,1.21 \\
0.62,1.27 \\
0.70,1.40 \\
0.56,1.15\end{array}$ & 0.003 & No & No \\
\hline $\begin{array}{l}\text { Gonzalez } \\
\text { (2012) [16] }\end{array}$ & $\begin{array}{l}\text { EPIC-EUR- } \\
\text { GAST }\end{array}$ & $\begin{array}{c}477,312 \& 683 \\
\text { (11) }\end{array}$ & $F F Q$ & Citrus & $\begin{array}{l}\text { Q1 } \\
\text { Q2 } \\
\text { Q3 } \\
\text { Q4 } \\
\text { Q5 } \\
\text { Q1 } \\
\text { Q2 } \\
\text { Q3 } \\
\text { Q4 } \\
\text { Q5 } \\
\text { Q1 } \\
\text { Q2 } \\
\text { Q3 } \\
\text { Q4 } \\
\text { Q5 }\end{array}$ & $\begin{array}{l}1.00 \\
0.78 \\
0.84 \\
0.63 \\
0.87 \\
1.00 \\
0.73 \\
0.73 \\
0.54 \\
0.61 \\
1.00 \\
0.93 \\
1.07 \\
0.79 \\
1.25\end{array}$ & $\begin{array}{c}\text { Overall } \\
0.62,0.99 \\
0.67,1.07 \\
0.49,0.82 \\
0.68,1.12 \\
\text { Cardia } \\
0.49,1.08 \\
0.48,1.11 \\
0.34,0.85 \\
0.38,1.00 \\
\text { Non-cardia } \\
0.64,1.34 \\
0.75,1.53 \\
0.54,1.16 \\
0.86,1.80\end{array}$ & 0.01 & Yes & No \\
\hline
\end{tabular}

RR, relative risk; $\mathrm{Cl}$, confidence interval; NIH-AARP, National Institutes of Health-American Association of Retired Person; EPIC-EURGAST, European Prospective Investigation into Cancer and Nutrition; FFQ, food frequency questionnaire. 
used, and the lower bound value was set as zero if the lowest intake interval was open. If the highest intake interval was open, a median value of the adjacent interval was added to the low boundary of the interval [30,31]. The unit of citrus fruit intake was set as grams/day (g/d). Level of statistical significance was set at 5\%, and the Stata version 14.0 (StataCorp, College Station,TX, USA) statistical program was used (www.stata.com).

\section{RESULTS}

Figure 1 shows a flow chart illustrating a series of steps involved in the final selection of articles to be used in the analysis including the searching and evaluating processes. After applying the CDT on the two databases (PubMed and Scopus) based on the eight articles selected in the meta-analysis in Fang et al. [11], we obtained 12,164 records. After combining these records with 32 other records identified through manual searching, we eliminated 8,025 duplicated records. Among the 4,171 remaining records, 3,712 were eliminated based on abstract contents. Copies of the remaining 459 abstracts were obtained and their contents screened, leading to elimination of 454 articles. Five cohort studies were finally selected for the meta-analysis [16-
19,32]. A total of 4,166 articles were excluded according to the exclusion criteria: (1) 310 laboratory studies, (2) 972 expert/ SRs, (3) 2,430 descriptive studies, (4) 398 analytical studies that do not provide information necessary for the meta-analysis, (5) 52 case-control studies, (6) 2 gastric cancer mortality-based cohort studies [14,15], and (7) 2 cohort studies that were duplicated as a result of extending the follow-up period $[12,13]$.

Table 1 summarizes the characteristics of the five cohorts that were finally selected. Geographical regions included the US, Japan, China, the Netherlands, and Europe. The follow-up period length was 4.5 years at the minimum, and 11 years at the maximum, and the quantity of citrus fruit intake was measured by food frequency questionnaire (FFQ). aRR calculation was adjusted for smoking in all five articles, and it was also adjusted for total energy intake in four of the articles (Steevens et al. [17] not included). It was not adjusted for Hp infections in all of the articles.

Figure 2 is a forest plot showing effect size with $95 \% \mathrm{CI}$ obtained by applying the ICM on aRRs and their corresponding 95\% CIs in eight databases from five cohorts based on sex and anatomical region. Gonzalez et al. [16] not only calculated aRRs for the anatomical regions, but also reported an overall aRR pertinent to the total cohort population, so that the relative risks (RRs) for overall gastric cancer were used in the meta-analysis

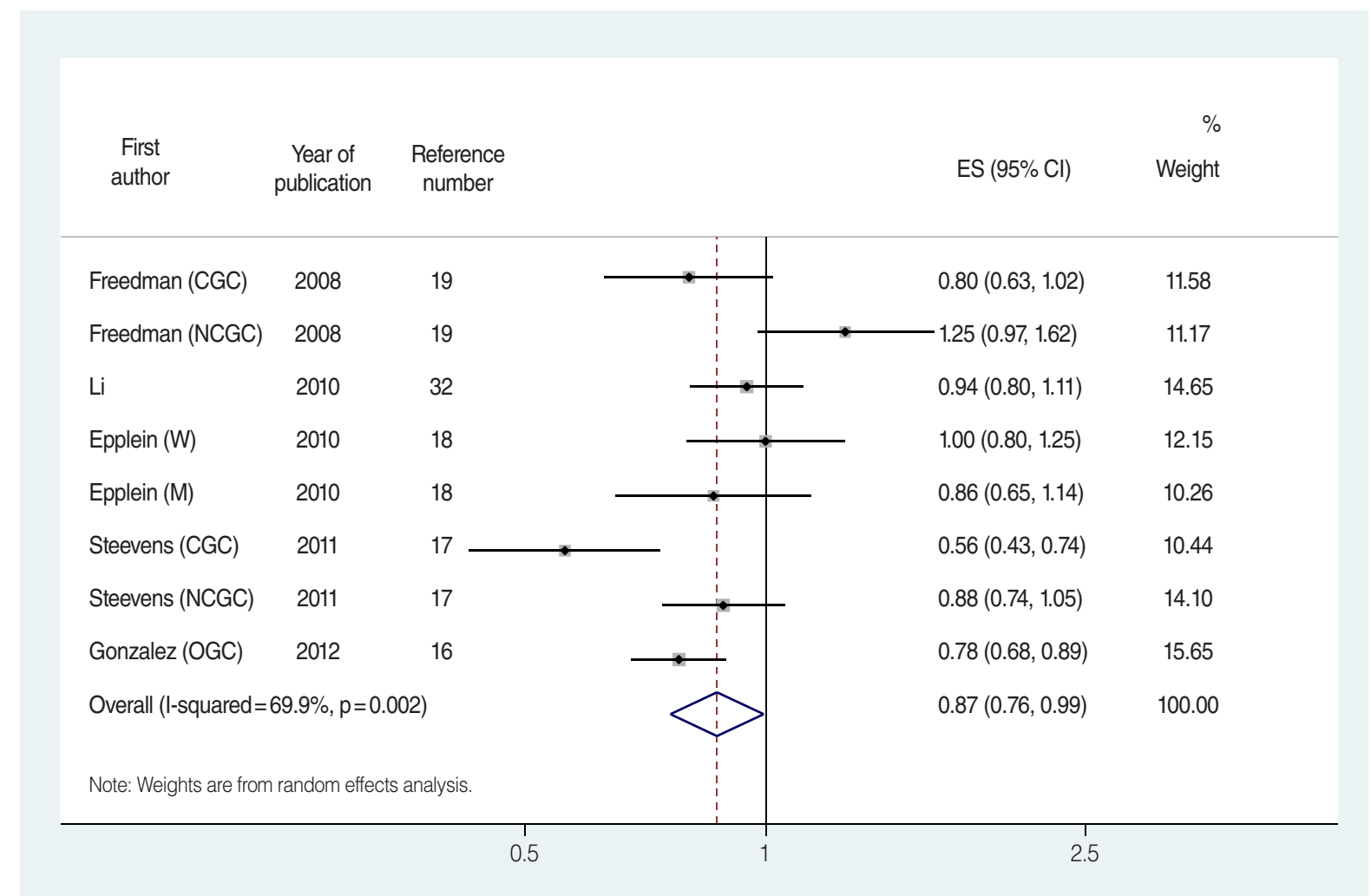

Figure 2. The forest plot of effect size (ES) and its 95\% confidence intervals (Cl) using a random effect model in eight datasets from five cohort studies. M, men; W, women; CGC, cardia gastric cancer; NCGC, non-cardia gastric cancer. 


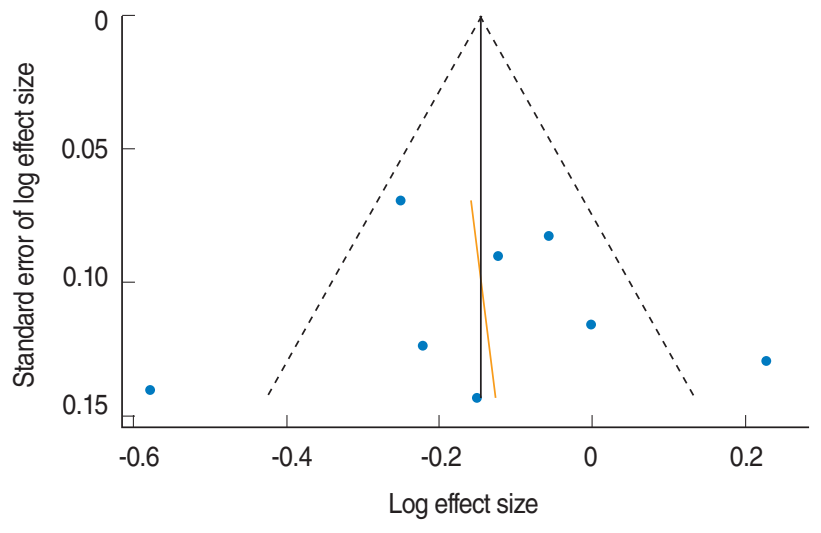

Figure 3. Funnel plot with pseudo 95\% confidence limits in eight datasets from five cohort studies.

for estimating overall effect. The $\mathrm{sES}$ of the eight datasets was 0.87 (95\% CI, 0.76 to 0.99 ; I-squared $=69.9 \%$ ), and citrus fruit intake inhibited gastric cancer development with statistical significance. An Egger's test was performed because moderate heterogeneity was detected. Small study effects were negligible (coefficient of bias $=0.43$; $\mathrm{p}$-value $=0.89$ ), and bilateral symmetry could be observed in the funnel plot (Figure 3).

In the subgroup analysis of each anatomical region, it was found that non-cardia gastric cancer had no statistical significance in relation to citrus fruit intake (sES, 0.95; 95\% CI, 0.78 to 1.15 ; I-squared $=77.5 \%$ ). However, citrus fruit intake had inhibitory effects on the development of cardia gastric cancer (CGC), and also had a statistically significant relationship with CGC risk (sES , 0.67; 95\% CI, 0.55 to 0.81 ; I-squared $=46.1 \%$ ) (Table 2). Of the five cohort studies, Steevens et al. [17] provided information regarding CGC that could be used in a RE-DRMR. Table 3 shows the RE-DRMR results. There was statistical significance in the relationship between citrus fruit intake and CGC risk $(p$-value $=0.002)$, and it was found that an intake of $100 \mathrm{~g}$ of citrus fruit per day reduced CGC risk by $40 \%$ (RR, $0.603 ; 95 \%$ CI, 0.439 to 0.827 ).

\section{DISCUSSION}

To summarize the results, dietary intake of citrus fruit reduced gastric cancer risk by $13 \%$, and had an inhibitory effect on CGC in particular. Since the subgroup analysis and RE-DRMR analysis showed that citrus fruit intake has no statistical significance with respect to NGC, it can be inferred that citrus fruit intake inhibits the development of CGC. With antioxidant supplement found to have no anticancer effects [33-35], the result of this study becomes a positive evidence for gastric cancer prevention.
Table 2. Subgroup analysis by anatomical location of stomach cancer

\begin{tabular}{lcccc}
\hline Subgroup & $\begin{array}{c}\text { Reference } \\
\text { number }\end{array}$ & sES & $95 \% \mathrm{Cl}$ & I-squared (\%) \\
\hline Incidence & $16-19,32$ & 0.87 & $0.76,0.99$ & 61.3 \\
Non-cardia & $16,17,19$ & 0.95 & $0.78,1.15$ & 77.5 \\
Cardia & $16,17,19$ & 0.67 & $0.55,0.81$ & 46.1 \\
\hline
\end{tabular}

sES, summary effective size; $\mathrm{Cl}$, confidence interval.

Table 3. Relative risks (RRs) ${ }^{1}$ of dose-response meta-regression using RRs of cardia gastric cancer in Steevens et al. [17]

\begin{tabular}{lcc}
\hline Intake of citrus fruits $(\mathrm{g} / \mathrm{d})$ & RR & 95\% confidence interval \\
\hline 1 & 0.995 & $0.992,0.998$ \\
10 & 0.951 & $0.921,0.981$ \\
20 & 0.904 & $0.848,0.963$ \\
25 & 0.881 & $0.814,0.924$ \\
50 & 0.776 & $0.663,0.910$ \\
75 & 0.684 & $0.540,0.868$ \\
100 & 0.603 & $0.439,0.827$ \\
\hline
\end{tabular}

${ }^{1} \mathrm{p}$-value $=0.002$.

The present study differs from the SR done by Fang et al. [11] in terms of the two methodologies used. First, whereas Fang et al. [11] used electronic searching during the data searching process, our study used the CDT strategy [26]. This strategy was developed while taking into account the fact that studies that share the same hypothesis cite articles that have already been selected in existing SRs, and are also similar in their contents. Therefore, we were able to additionally obtain a study [32] that should have been selected in Fang et al. [11], and also exclude two duplicated cohort studies $[12,13]$ that used the same cohort source. In other words, an adaptive meta-analysis method using the CDT had a lower omission rate compared to electronic searching, and allowed for a more valid selection of studies [22,23]. Secondly, our study differs in that it uses the ICM approach rather than the HLM approach to extract datasets from the selected studies to be used in the meta-analysis [26]. As a result, the directionality of $\mathrm{sES}$ in our study was closer towards "against null" than Fang et al. (0.90 vs. 0.87) [11]. Our study had a wider CI (0.82 to 1.00 vs. 0.76 to 0.99$)$, but this could not be included in the comparison because our study excluded two cohort studies $[14,15]$ that were mortality-based. After adding in these two cohort studies, the sES using ICM was on par with that in Fang et al. [11] at 0.90, and the 95\% CI narrowed to 0.83 to 0.97 (Table 2). In other words, by using the ICM approach, we were able to further increase statistical power and obtain more accurate results [26].

This study has some limitations. First, none of the five selected cohort studies was adjusted for Hp infection. This may be due to the difficulty in performing Hp tests on all of the study 
participants during cohort establishment, with the importance of Hp infections being acknowledged only recently $[10,36]$. However, it is possible to obtain information regarding $\mathrm{Hp}$ infection and adjust for it through nested case-control studies (NCCS). A SR of 12 studies that utilized this NCCS method suggested that Hp infection was not associated with CGC risk (sES, $0.99 ; 95 \%$ CI, 0.72 to 1.35) [37]. If we accept this conclusion, it would be valid to say that citrus fruit intake has inhibitory effects on CGC even if the five cohort studies selected in our study were not adjusted for Hp infections. On the other hand, Hansen et al. [38] concluded that Hp infection-induced gastric atrophy is a risk factor of CGC, while Hp infection is not a direct risk factor of CGC. It is necessary to perform additional SRs on studies that were performed based on a NCCS design. Secondly, there were still not enough cohort studies selected to draw any results regarding CGC in different anatomical regions. Two studies were selected from the studies that were published until April 2007 [8], and five were selected from the studies that were published until December 2015 [11]. Although Bae et al. [8] could not establish any statistical significance in the relationship between citrus fruit intake and gastric cancer development in the meta-analysis, our study, with the addition of three more articles, was able to gain statistical significance. However, only three of the five selected cohort studies were used when we looked at gastric cancer risk for each anatomical region $[16,17$, 19]. Since no statistical significance was observed for NGC in our meta-analysis, it would be necessary to extend the cohort follow-up period and do a pooled analysis. Third, only one study provided information that could be used in the RE-DRMR. However, it was found that $100 \mathrm{~g} / \mathrm{d}$ of citrus fruit intake reduced risk of gastric cancer incidence by $40 \%$. On the other hand, Vingeliene et al. [39] reported that the same amount of citrus fruit intake could not lower mortality risk of gastric cancer (RR, 0.95; $95 \%$ CI, 0.85 to 1.05). More studies must be done with additional information regarding cohort studies.

\section{CONCLUSION}

To summarize the results, dietary intake of citrus fruit inhibits the development of gastric cancer, especially CGC. With the growing trend in the incidence of CGC and the decreasing trend in the incidence of NGC [20], this finding may be used as part of a dietary improvement strategy for gastric cancer prevention.

\section{CONFLICT OF INTEREST}

The authors have no conflicts of interest to declare for this study.

\section{SUPPLEMENTARY MATERIAL}

Supplementary material (Korean version) is available at http: //www.e-epih.org/.

\section{ORCID}

Jong-Myon Bae http://orcid.org/0000-0003-3080-7852

Eun Hee Kim http://orcid.org/0000-0002-1065-1080

\section{REFERENCES}

1. Torre LA, Bray F, Siegel RL, Ferlay J, Lortet-Tieulent J, Jemal A. Global cancer statistics, 2012. CA Cancer J Clin 2015;65:87-108.

2. Parkin DM. The global health burden of infection-associated cancers in the year 2002. Int J Cancer 2006;118:3030-3044.

3. Wroblewski LE, Peek RM Jr, Wilson KT. Helicobacter pylori and gastric cancer: factors that modulate disease risk. Clin Microbiol Rev 2010;23:713-739.

4. Wroblewski LE, Peek RM Jr. Helicobacter pylori in gastric carcinogenesis: mechanisms. Gastroenterol Clin North Am 2013;42:285-298.

5. Guggenheim DE, Shah MA. Gastric cancer epidemiology and risk factors. J Surg Oncol 2013;107:230-236.

6. Nagini S. Carcinoma of the stomach: a review of epidemiology, pathogenesis, molecular genetics and chemoprevention. World J Gastrointest Oncol 2012;4:156-169.

7. Tsugane S, Sasazuki S. Diet and the risk of gastric cancer: review of epidemiological evidence. Gastric Cancer 2007;10:75-83.

8. Bae JM, Lee EJ, Guyatt G. Citrus fruit intake and stomach cancer risk: a quantitative systematic review. Gastric Cancer 2008;11:23-32.

9. Martínez ME, Marshall JR, Giovannucci E. Diet and cancer prevention: the roles of observation and experimentation. Nat Rev Cancer 2008;8:694-703.

10. Musa-Veloso K, Card JW, Wong AW, Cooper DA. Influence of observational study design on the interpretation of cancer risk reduction by carotenoids. Nutr Rev 2009;67:527-545.

11. Fang X, Wei J, He X, An P, Wang H, Jiang L, et al. Landscape of dietary factors associated with risk of gastric cancer: a systematic review and dose-response meta-analysis of prospective cohort studies. Eur J Cancer 2015;51:2820-2832.

12. Botterweck AA, van den Brandt PA, Goldbohm RA. A prospective cohort study on vegetable and fruit consumption and stomach cancer risk in The Netherlands. Am J Epidemiol 1998;148:842-853.

13. González CA, Pera G, Agudo A, Bueno-de-Mesquita HB, Ceroti M, Boeing $\mathrm{H}$, et al. Fruit and vegetable intake and the risk of stomach and oesophagus adenocarcinoma in the European Prospective Investigation into Cancer and Nutrition (EPIC-EURGAST). Int J Cancer 2006; 118:2559-2566.

14. McCullough ML, Robertson AS, Jacobs EJ, Chao A, Calle EE, Thun MJ. A prospective study of diet and stomach cancer mortality in United States men and women. Cancer Epidemiol Biomarkers Prev 2001; 10:1201-1205.

15. Jansen MC, Bueno-de-Mesquita HB, Räsänen L, Fidanza F, Menotti A, Nissinen A, et al. Consumption of plant foods and stomach cancer mortality in the seven countries study. Is grain consumption a risk factor? Seven Countries Study Research Group. Nutr Cancer 1999;34: 
49-55.

16. Gonzalez CA, Lujan-Barroso L, Bueno-de-Mesquita HB, Jenab M, Duell EJ, Agudo A, et al. Fruit and vegetable intake and the risk of gastric adenocarcinoma: a reanalysis of the European Prospective Investigation into Cancer and Nutrition (EPIC-EURGAST) study after a longer follow-up. Int J Cancer 2012;131:2910-2919.

17. Steevens J, Schouten LJ, Goldbohm RA, van den Brandt PA. Vegetables and fruits consumption and risk of esophageal and gastric cancer subtypes in the Netherlands Cohort Study. Int J Cancer 2011;129: 2681-2693.

18. Epplein M, Shu XO, Xiang YB, Chow WH, Yang G, Li HL, et al. Fruit and vegetable consumption and risk of distal gastric cancer in the Shanghai Women's and Men's Health studies. Am J Epidemiol 2010;172:397-406.

19. Freedman ND, Subar AF, Hollenbeck AR, Leitzmann MF, Schatzkin $\mathrm{A}, \mathrm{Abnet} \mathrm{CC}$. Fruit and vegetable intake and gastric cancer risk in a large United States prospective cohort study. Cancer Causes Control 2008;19:459-467.

20. Forman D, Burley VJ. Gastric cancer: global pattern of the disease and an overview of environmental risk factors. Best Pract Res Clin Gastroenterol 2006;20:633-649.

21. Liberati A, Altman DG, Tetzlaff J, Mulrow C, Gøtzsche PC, Ioannidis JP, et al. The PRISMA statement for reporting systematic reviews and meta-analyses of studies that evaluate healthcare interventions: explanation and elaboration. BMJ 2009;339:b2700.

22. Bae JM, Kim EH. Citation discovery tools for conducting adaptive meta-analyses to update systematic reviews. J Prev Med Public Health 2016;49:129-133.

23. Bae JM, Kim EH. Human papillomavirus infection and risk of breast cancer: a meta-analysis of case-control studies. Infect Agent Cancer 2016;11:14.

24. Bae JM, Kim EH. Hormonal replacement therapy and the risk of lung cancer in women: an adaptive meta-analysis of cohort studies. J Prev Med Public Health 2015;48:280-286.

25. Bae JM. Human papillomavirus 16 infection as a potential risk factor for prostate cancer: an adaptive meta-analysis. Epidemiol Health 2015; 37:e2015005.

26. Bae JM. Comparison of methods of extracting information for metaanalysis of observational studies in nutritional epidemiology. Epidemiol Health 2016;38:e2016003.

27. Egger M, Davey Smith G, Schneider M, Minder C. Bias in meta-anal- ysis detected by a simple, graphical test. BMJ 1997;315:629-634.

28. Harbord RM, Egger M, Sterne JA. A modified test for small-study effects in meta-analyses of controlled trials with binary endpoints. Stat Med 2006;25:3443-3457.

29. Orsini N, Bellocco R, Greenland S. Generalized least squares for trend estimation of summarized dose-response data. Stata J 2006;6:40-57.

30. Xu X, Yu E, Liu L, Zhang W, Wei X, Gao X, et al. Dietary intake of vitamins $\mathrm{A}, \mathrm{C}$, and $\mathrm{E}$ and the risk of colorectal adenoma: a meta-analysis of observational studies. Eur J Cancer Prev 2013;22:529-539.

31. Wang X, Ouyang Y, Liu J, Zhu M, Zhao G, Bao W, et al. Fruit and vegetable consumption and mortality from all causes, cardiovascular disease, and cancer: systematic review and dose-response meta-analysis of prospective cohort studies. BMJ 2014;349:g4490.

32. Li WQ, Kuriyama S, Li Q, Nagai M, Hozawa A, Nishino Y, et al. Citrus consumption and cancer incidence: the Ohsaki cohort study. Int J Cancer 2010;127:1913-1922.

33. Bjelakovic G, Nikolova D, Simonetti RG, Gluud C. Antioxidant supplements for prevention of gastrointestinal cancers: a systematic review and meta-analysis. Lancet 2004;364:1219-1228.

34. Huang HY, Caballero B, Chang S, Alberg AJ, Semba RD, Schneyer $\mathrm{CR}$, et al. The efficacy and safety of multivitamin and mineral supplement use to prevent cancer and chronic disease in adults: a systematic review for a National Institutes of Health state-of-the-science conference. Ann Intern Med 2006;145:372-385.

35. Li P, Zhang H, Chen J, Shi Y, Cai J, Yang J, et al. Association between dietary antioxidant vitamins intake/blood level and risk of gastric cancer. Int J Cancer 2014;135:1444-1453.

36. Temple NJ. Nutrition and disease: challenges of research design. Nutrition 2002;18:343-347.

37. Helicobacter and Cancer Collaborative Group. Gastric cancer and Helicobacter pylori: a combined analysis of 12 case control studies nested within prospective cohorts. Gut 2001;49:347-353.

38. Hansen S, Vollset SE, Derakhshan MH, Fyfe V, Melby KK, Aase S, et al. Two distinct aetiologies of cardia cancer; evidence from premorbid serological markers of gastric atrophy and Helicobacter pylori status. Gut 2007;56:918-925.

39. Vingeliene S, Chan DS, Aune D, Vieira AR, Polemiti E, Stevens C, et al. An update of the WCRF/AICR systematic literature review on esophageal and gastric cancers and citrus fruits intake. Cancer Causes Control 2016;27:837-851. 